\title{
Nitrilotriacetic Acid
}

National Cancer Institute

\section{Source}

National Cancer Institute. Nitrilotriacetic Acid. NCI Thesaurus. Code C44408.

A white, crystalline solid compound. Nitrilotriacetic acid is mainly used as a chelating and eluting agent and is found in laundry detergents. Exposure to Nitrilotriacetic acid irritates the skin, eyes and respiratory tract and causes kidney and bladder damage. Nitrilotriacetic acid is reasonably anticipated to be a human carcinogen. ( $\mathrm{NCl05})$ 